\title{
A Pacchionian Puzzle
}

\author{
M. Nazir Khan, Brett H. Shaw (D, Carla J. Wallace, Luanne Metz
}

Keywords: Ataxia, Neurology - Adult

doi:10.1017/cjn.2019.318

Can J Neurol Sci. 2020; 47: 231-232

A 73-year-old male with a history of chronic ataxia presented with transient facial droop to the Emergency Department. A CT angiogram and MRI with diffusion weighted imaging (DWI) were negative for stroke. However, incidental note was made of numerous giant arachnoid granulation pits in the posterior fossa predominantly involving the left occipital bone (Figure 1). These arachnoid pits demonstrated multiple foci of herniation of the adjacent cerebellar parenchyma into the pits with gliosis of the herniated parenchyma and focal encephalomalacia of the subjacent cerebellar parenchyma. Review of bone windows on a remote CT brain performed almost 13 years earlier confirmed this to be a longstanding abnormality (Figure 2). The patient's physical exam was suggestive of cerebellar ataxia with leftsided dysmetria on finger to nose testing and a wide-based unsteady gait.

Arachnoid granulations (also called Pacchionian granulations after the Italian physician Antonio Pacchioni) are normal anatomical structures that facilitate the return of cerebrospinal fluid to the venous system through the dural venous sinuses. ${ }^{1}$
Giant arachnoid granulation pits are considered to be of large size $(>1 \mathrm{~cm})^{2}$ or causing filling defects in the dural venous sinus. $^{3}$ They are commonly located near the cerebral venous sinuses but have been reported to be found in other locations. ${ }^{1,4}$ At times, they are noted to extend into the inner table of the skull and can create osteolytic lesions, as in this case. ${ }^{1}$ The occipital bone is a rare location to find granulation pits.,4 Although typically asymptomatic, their role in cerebrospinal fluid leaks has been described ${ }^{4}$ and they may account for neurological symptoms when large or when they contain herniated brain parenchyma. ${ }^{5}$

\section{ACKNOWLedGements}

None.

\section{Disclosures}

The authors have no conflicts of interest to declare.
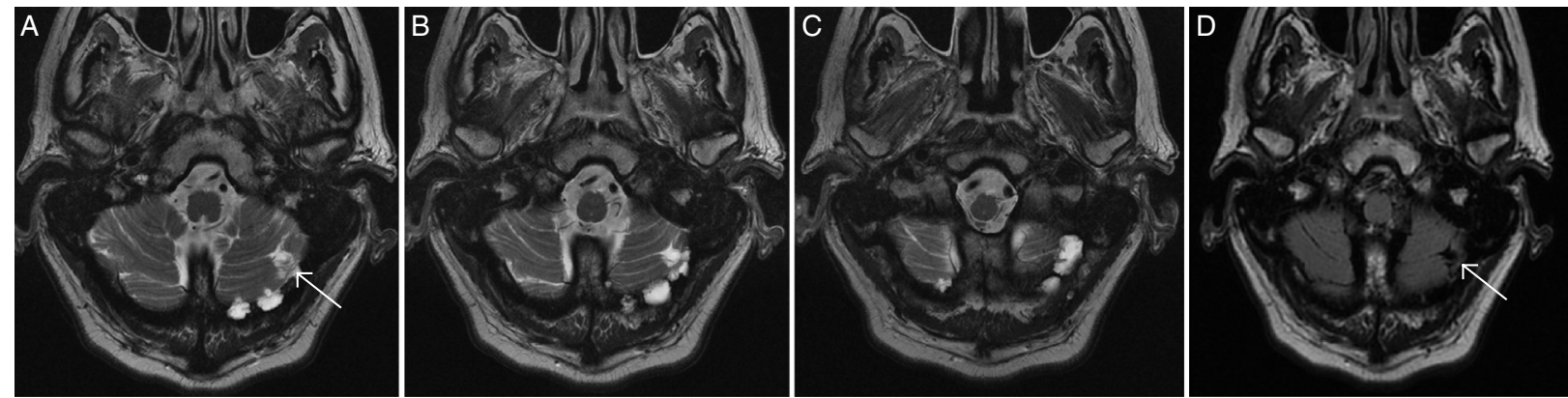

Figure 1: $(A-D)$ MRI images of extensive arachnoid granulation pits in the posterior fossa. T2 images (A-C) from an MRI brain demonstrating extensive arachnoid granulation pits in the posterior fossa predominantly involving the left occipital bone. A FLAIR image (D) illustrates parenchymal gliosis associated with the arachnoid granulation herniation pits.

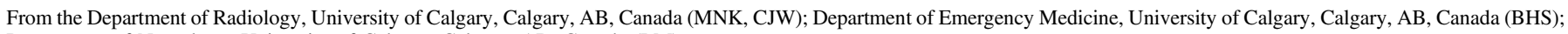
Department of Neurology, University of Calgary, Calgary, AB, Canada (LM)

Received July 14, 2019. Final Revisions Submitted September 22, 2019. Date of Acceptance October 18, 2019.

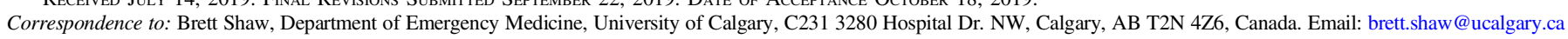




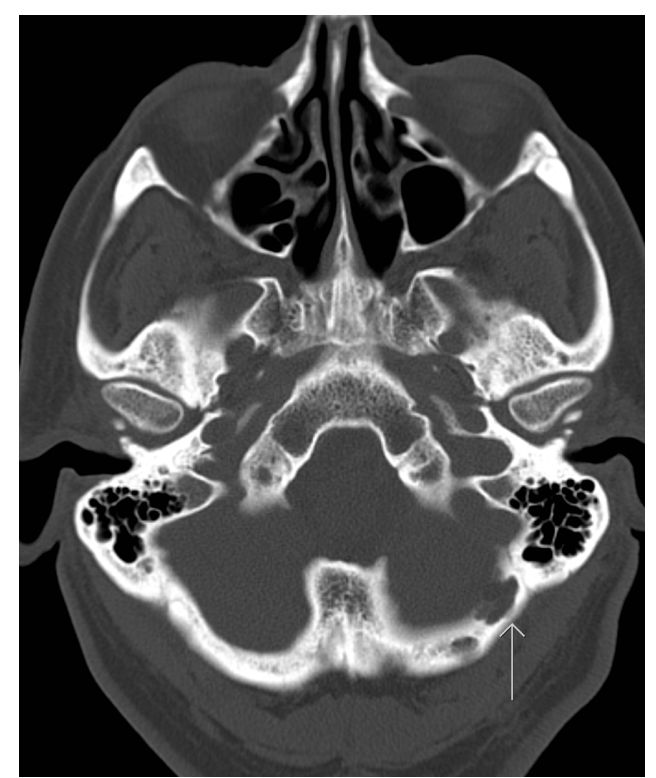

\section{Statement of Authorship}

MNK, BHS, CJW, and LM were all involved with the drafting and editing of this manuscript.

\section{REFERENCES}

1. Ogul H, Kantarci M. An unusual cause of progressive headache: herniation of the cerebellar gyrus into the intraosseous arachnoid granulation. Headache 2017;57:778-9.

2. Trimble CR, Harnsberger HR, Castillo M, Brant-Zawadzki M, Osborn AG. "Giant" arachnoid granulations just like CSF?: NOT!!. Am J Neuroradiol. 2010;31(9):1724-8.

3. Kan P, Stevens EA, Couldwell WT. Incidental giant arachnoid granulation. Am J Neuroradiol. 2006;27(7):1491-2.

4. Lee MH, Kim H-J, Lee IH, Kim ST, Jeon P, Kim KH. Prevalence and appearance of the posterior wall defects of the temporal bone caused by presumed arachnoid granulations and their clinical significance: CT findings. Am J Neuroradiol. 2008;29(9):1704-7.

5. Liebo GB, Lane JJ, Van Gompel JJ, Eckel LJ, Schwartz KM, Lehman VT. Brain herniation into arachnoid granulations: clinical and neuroimaging features. J Neuroimaging 2016;26(6):592-8.

Figure 2: CT bone window image of arachnoid granulation pits in the posterior fossa. 